\title{
Training Partnerships in the NHS: targeting Information Technology
}

\section{Introduction}

The National Health Service (NHS) in the United Kingdom is going through a period of rapid change in the use of Information Technology (IT). This was clearly stated in the recent Government White Paper, The new NHS: Modern, dependable. The aim of the Information Technology and Management Strategy for the NHS is to harness the enormous potential benefits of IT to support the drive for quality and efficiency by:

- making patient records electronically available when they are needed;

- using the NHS net and the internet to bring patients quicker test results, on-line booking of appointments and up-to-date specialist advice; 
- enabling accurate information about finance and performance to be available promptly;

- providing knowledge about health, illness and best treatment practice to the public through the internet, and emerging public access media (e.g. digital TV); and

- developing telemedicine to ensure specialist skills are available to all parts of the country. (DOH, 1997)

With such a wide reaching change agenda the implications for staff development in IT skills is enormous. This article is concerned with how to deal with the problem of providing IT skills training for staff within the NHS given the pressures on time and resources.

This paper is structured as follows. Firstly, it will briefly review the literature on work-based learning and partnerships between employers and education providers. It will describe and analyse how one NHS trust hospital tackled IT training in partnership with a college of further education. The paper will conclude by outlining the lessons from the partnership and how this approach could benefit other NHS organisations in addressing their IT training needs. 


\section{Employer and Education Partnerships}

The concept of partnership between employers and education providers has been well documented in major UK reports (Handy, 1987; Constable and McCormick, 1987). However, there are few accounts reporting on partnerships within the NHS. Those that are produced offer little description or critical analysis of practice (IRS, August 1997). This article attempts to redress the balance.

It is clear that a wide variety of partnerships exist between employers and education establishments. These range, for example, from the consortium programmes for specialist management awards (Edwards, Loveys and Wareing, 1993) to the provision of bespoke singlecompany solutions (Ashton, 1989). Other approaches involve highly developed industry-academic partnerships (Keithley and Redman, 1997), developing 'learning organisations' through partnership (Iles, Hickie and Smylie, 1995) to the placing of students on in-company projects to act as consultants (Linstead, 1993). There are also more adhoc relationships involving specific and relatively small training programmes (Redman and Allen, 1993) to the development of secondments (Lantos, 1994). The literature on partnerships tends to focus on success stories, which makes the process appear relatively 
straight forward and trouble free. This paper seeks to provide an account of the benefits and problems encountered in practice.

\section{Methodology}

This article will draw upon the author's direct experience of managing a training partnership to address IT skill needs between a hospital trust and a college of further education. The report of the case study analyses the key events that took place between 1995 and 1997 from direct observation, discussion and records of meetings with key people involved in the partnership. A final source of information comes from the author's analysis of evaluation questionnaires completed by course participants.

\section{Partnership Background}

The NHS Health Trust in question is a combined acute, community and mental health hospital in the North of England. It has approximately 2,800 employees and a turnover of $£ 60$ million. The organisation has been under pressure over the last five years to develop the use of IT within the organisation. This pressure has come from the NHS Management Executive centrally to develop the 
IT capability of NHS organisations. The IT systems in use also needed to be developed to meet the ever increasing demands for information from patients, GPs, Health Authorities and other users of the service. Pressure had also come from the rapidly developing new technology in clinical fields such as telemedicine and communication systems in the shape of the Internet and the electronic patient record.

The drive for change was given added impetus, with the appointment of a new Chief Executive to the Trust in 1995 who had IT development at the top of his agenda. This new Chief Executive headed up an IT Strategy Group which dealt with organisation wide IT issues. These ranged from authorising the purchase of IT equipment, overseeing the development of computer systems to IT training. It was the area of training that was seen as too large and complex for the group to tackle and a sub group was formed in 1994 to deal with the issue of IT training. After some initial changes of personnel the IT sub group was made up of two senior managers, a representative from Training and Development (the author) and the Information and IT Manager. The sub group was charged with carrying out a training needs analysis and organising the necessary IT training for the organisation. The hospital did not have a dedicated IT training team and relied on adhoc support from staff in the 
Information and IT department who had other jobs to perform. The organisation had no data on IT training needs and no real provision for IT training in-house.

\section{The College of Further Education}

The partnership between the college of further education and the NHS trust began in the spring of 1995 when representatives from the Training and Development department at the NHS trust hospital met with the IT Manager of the college to discuss IT training. This initial meeting led to around sixty administration and management staff undertaking basic computer training at the college. This training was low in cost and from informal discussions with a cross section of the participants it was of good quality providing them with a detailed workbook and one to one tuition. The key difficulty encountered at this stage was that staff had the inconvenience of travelling some distance to the college.

As this initial arrangement ended it raised the possibility of the college working with the hospital in the future within the area of IT training. The college had recently merged with a sixth form college and was operating on two sites. Historically it had specialised in 
areas such as engineering and construction but was looking to expand other areas such as IT. Incorporation of further education colleges in 1993 had led to a more market driven approach to their activities. This resulted in the particular college in question establishing a team of people dedicated to generating business from local employers. As part of these changes colleges of further education became free from the constraints of local planning. This resulted in demand led funding which was designed to promote growth. It was this change in funding and operating arrangements that opened up the possibility of the college forming an ongoing partnership with the hospital.

\section{The Work-Based Learning Approach}

The IT sub group felt that work-based learning (WBL) was the right approach to take in reaching the diverse range of staff within the hospital who needed IT training. WBL is viewed as an essential cornerstone of Human Resource Development and a core element of the partnership approach (Megginson, Matthews and Banfield, 1993). Experiential learning of this nature can have a much greater relevance to the workforce. There are a number of approaches to WBL many of which are simply the formalising of informal training processes such as coaching and mentoring programmes. WBL is 
usually delivered via short modular courses and funded by

employers. The employer is often seen as the main beneficiary from WBL as employees are usually compelled to attend and they gain horizontal expansion of skills rather than upward career progression (Roberts and Corcoran-Nantes, 1995). Other approaches to workbased learning include action learning (Revans, 1970) through to the competence and National Vocational Qualification (NVQ) movement and most latterly via the learning organisation (Burgoyne, 1995).

The WBL approach fitted into the training plans of the IT sub group as there was going to be an element of compulsion and costs had to be kept to a minimum. The competence and NVQ approach was felt appropriate because it would ensure the staff were training to national standards in using IT and an NVQ certificate was an incentive for many of them to attend.

\section{Identifying IT Training Requirements}

In late 1995 the IT Training sub group within the Hospital quickly realised that before any detailed work could be undertaken hard data on the organisations training needs was required. The group decided to carry out a training survey amongst all existing IT users within the 
hospital. This survey was sent to all the senior managers on the IT strategy group who represented all Directorates within the hospital. It was their responsibility to ensure all departments completed the survey and to subsequently collate the information on training needs.

The areas identified by the sub group on the survey form were taken from the generic computer systems being used within the hospital. These ranged from basic computer skills, word processing, use of spreadsheets, etc., through to analytical skills. At this point the subgroup had not decided the specific criteria for each of these areas as it was anticipated, even at this stage, that an outside provider would draw up the detailed training specification. The survey results were as follows:

Subject Area Number of staff Requiring Training

Basic computer skills 585

Keyboard skills 605

Spreadsheet training

Word processing 
These results came from an estimated 1200 IT users in the Trust and were felt to be fairly accurate figures. It was decided by the sub group to concentrate on the first four areas as they had the largest numbers requiring training. The problem for the group was how the training was going to be delivered given the numbers involved, the very limited budget available and a lack of skilled in-house trainers. One area that could be developed and which eventually became a focus for the training was an IT training room with twelve computers, which was under-utilised. In February 1996, the IT Training sub group decided to put the IT training contract out to tender. A range of training providers were invited to submit bids such as a local training provider, a national company and a local college. Many of these providers were selected because they had been used by the Trust in the past or they had been personally recommended. On receiving the bids a summary list was compiled with costs attached and put forward to the IT Strategy group for consideration. The outcome was perhaps inevitable as the cost ranged from thousands in the proposal from the national company to virtually no cost from the college. The local college of further education was accepted as the 
preferred provider and asked to draw up a detailed proposal. It was around this time that the IT Manager from the college informed us of the Further Education Funding Council (FEFC) demand-led funding available to help enrol staff onto training courses.

\section{Establishing the Partnership}

The contract that the IT sub group negotiated with the college was to provide the training on site at no cost. The college was willing to accept this arrangement provided that at least 500 staff registered with the college to complete an NVQ Level One in using IT. This arrangement enabled the college to tap into the demand led funding which was available. This made the partnership financially lucrative and provided an opportunity for the college to raise its profile by working with a large local employer. The costs to the hospital were the use of the IT training room for around six months, staff time and replacement costs to attend training and the production of literature to promote the training.

The contract with the college was for twenty weeks initially. The partnership was going to address an important organisational development issue in making sure all IT users had up to date skills 
and that competency based training would be embedded across the organisation at all levels from staff nurse to director. The training was to take place on the basis of a target of 500 staff to attend a series of one-day computer training sessions at the hospital. A college lecturer and assessor were to be seconded to deliver training on-site and they would conduct a short interview with each candidate to determine prior learning. A number of work placement students were going to help with the administration associated with the training. A process of evidence collection and work place assessment was to be carried out to develop a portfolio of evidence for all staff. A training day of six hours was to be provided as part of a rolling programme co-ordinated by the Training and Development Department.

The initial target of 500 staff was felt to be a realistic number with clinical areas needing a minimum of six weeks notice for organising staff rota patterns. If it was deemed appropriate by the line manager staff could move through the programme and attend more than one course. 


\section{The Partnership in Action}

The training commenced in April 1996 after an intense period of promotion with the aim to secure up to twelve nominations for each course. Bringing the course to the hospital was beginning to bear fruit as staff such as senior clinicians who had been previously difficult to reach for training because of the hours they worked were beginning to enrol.

The training was being delivered in the dedicated IT Training room with twelve computers using a variety of methods such as group demonstration, lecture and one to one practical sessions. The college staff had produced a range of bespoke products such as workbooks for each course, booklets full of exercises and files with assessment documentation. The college was keeping detailed enrolment records so that all candidates could be contacted for workplace assessment and distribution of portfolios. Each course was being evaluated by completion of a questionnaire at the end. Whilst the initial training was underway the IT Training sub group negotiated another series of workshops. A further five weeks basic computer skills, word processing and spreadsheet training were organised along with three weeks of training in areas such as the use of advanced databases. 
This came to a total of twenty eight weeks training scheduled up to the end of 1996.

A few months into the training enrolment started to drop with only three or four members of staff attending some workshops. The college staff involved started to get concerned as they could not justify their investment of staff time and resources if the numbers did not reach the target figure of 500 as the college would not qualify for the demand led funding. A number of urgent meetings were held to review the situation and the Training and Development Department agreed to further promote the workshops. The senior management of the hospital was also informed and pressure was placed on departments to nominate staff. This incident made the IT training sub group realise how precarious the partnership arrangement was if targets were not met. From then on the college agreed to report regularly to the hospital on the number of people enrolling for training. Each directorate within the hospital had a senior manager responsible for ensuring that all IT users were nominated for the appropriate workshops. This press ganging of staff appeared to work as numbers started to rise after this point. The element of compulsion did not seem to have an adverse effect as many staff once they became aware of the training, perceived it as high quality because it 
was being delivered to national standards and there was a qualification on successful completion.

\section{Tackling Corporate Systems}

As the partnership arrangement progressed there was constant feedback to the IT strategy group and regular reviews between the college and the IT sub group. During the review meetings the feedback and progress of the training was very positive. It had been agreed that the WBL approach would involve all candidates being given a portfolio of records to complete such as an IT health and safety questionnaire, witness testimony from their line manager and assessment records. The college assessor either in the workplace or in the IT training room would assess the candidate by observation. The evaluations completed after each workshop were analysed and the majority was giving positive feedback. The statistics on the partnership programme on 1 July, 1996 were as follows:

Candidates attended to date

Candidates who had attended 2 courses

Candidates who have attended 3 courses 
Out of the 305 staff who had attended, two had left the programme because they had found employment elsewhere and only one person did not want to be involved with NVQs. The senior management of the hospital viewed the programme to date as a success and with these positive developments it meant that the IT Training sub group was instructed from the IT Strategy Group to look at corporate systems training for the Trust.

The issue of corporate systems training was raised with the college and although potentially difficult to fit into the FEFC funding criteria it was decided to press ahead as the partnership was proving so successful. The college tutor on completion of all the generic computer training now had to be trained in the new operating theatre computing system by hospital staff. This system urgently needed to be up and running with all key staff trained to use it. By January 1997 the college was ready to run training in the operating theatre systems along the same lines as before. Again all of the staff were to enrol for completion of an NVQ and the Trust systems training was sandwiched by more generic training to meet the funding criteria. 
The Hospital trust also wanted to tackle another training need, which was the Nurse Management Information System, used by the nursing staff on the wards. Previous training had been provided but the nominated trainer had retired and the approach was adhoc or in some places non-existent with two nurses providing training where they could. Again the college lecturer was trained up with the help of the two nurses concerned and the eight weeks of training was launched. The target figure was for 500 staff to be trained before the funding ran out at the end of July 1997. The training would be cascaded by the staff who attended the course to colleagues on the wards. Unfortunately the training day needed to be nine hours long to fit other generic training in and meet the funding criteria. The training had been organised quickly and there had been less planning and consultation as before. As a result the training was not as successful in terms of reaching the target figure of 500 with only just over one hundred nurses attending.

After analysing the course evaluations the IT Training sub group concluded they were positive about the quality of the training but stressed that the long day and repetition of training was deterring staff from attending. The hospital knew the funding was to end in July and at the same time the college was restructuring with a new 
principal and a new set of priorities. The results of the partnership were viewed as a success by both management and staff members who undertook the training. A total of 518 members of staff attended workshops in the first eight months with 182 attending more than one course. By the summer of 1997 just over 390 staff had gained an NVQ Level One in Using Information Technology.

\section{Conclusion}

This partnership was one of many forged with further education providers at this time. In the Northern and Yorkshire region of the NHS alone there was a similar training partnership in West Yorkshire and as a result of the partnership outlined in this paper two other hospital trusts in the Northern region set up smaller partnerships with the same college of further education.

Among the successful areas for other NHS organisations to note was that the Trust was able to offer a work based learning approach thus making it easier to target health care professionals. It started to help address organisational development issues such as the introduction of competency based training to a large number of staff who otherwise 
may not have been involved. It provided valuable evidence for a successful bid by the hospital for the Investors in people Award, and helped to achieve goals set out in the Human Resource and Organisation Development strategy. The training programmes raised the profile of IT training across the organisation and demonstrated the commitment of the organisation to staff development. The partnership started to deliver a bespoke solution to what had become a difficult and complex training issue.

There were a number of problems which arose from the partnership, for example the Trust became too reliant on the college for IT training and did not have a clearly defined follow up plan. As a result there were no arrangements in place to follow on from the partnership and it led to a long list of training needs being temporarily shelved. There were a number of issues which should have been tackled differently such as clearly defining the target group so that it reached IT users rather than being aimed at all staff. These led to a raising of expectations for some staff that they were going to attend training but in the end were not allowed to. It also meant that there were a relatively high number of candidates who had attended the training who were not regular IT users. 
The partnership faced a number of problems along the way with the major one being that it ended up as a short-term solution as the funding arrangements it was reliant on came to an end. It had failed what has been dubbed the acid test for this type of partnership (Keithley and Redman, 1997) in that it did not prosper over the long term and accommodate new contexts in a changing and competitive business environment. Perhaps the question of the elements needed to ensure that this type of partnership can last over the long term can be addressed in a future paper. On a wider note the model of skilltransference outlined in this paper may have possible applications in other sectors outside of the NHS. This again could form the basis of further research into business and education partnerships.

Whilst taking into account the issues raised above, this case study does demonstrate how a partnership of this nature can provide a way forward for NHS organisations to deal with their future IT training needs at a time when there is a large IT agenda within the Health Service. 


\section{References and further reading}

Ashton, D. (1989), "The case for tailor-made MBAs", Personnel Management, July, pp. 32-35.

Burgoyne, J. (1995), "Feeding minds to grow your business", People Management, Vol.1 No.19, pp. 22-24.

Constable, J., and McCormick, R. (1987), The Making of British Managers, BIM/CBI, London.

DOH (1997), The new NHS: Modern, dependable, HMSO, London.

Edwards, V., Loveys, R., and Wareing, T. (1993), "How to make partnerships work", Journal of European Industrial Training, Vol. 17 No. 3, pp. 3-6.

Handy, C. (1987), The Making of Managers, NEDO, London.

Iles, P., Hickie, D., and Smylie, G. (1995), “Developing learning organisations through company - academic partnerships: an interdisciplinary model and empirical evidence", Proceedings of the 
Strategic Direction of Human Resource Management Conference, Nottingham Trent University.

IRS (1997), "Training in unison - forging partnerships with employers", Employee Development Bulletin, No. 92, Employment Review, August.

Keithley, D., and Redman, T. (1997), "University - industry partnerships in management development, A case study of a 'worldclass company", Journal of Management Development, Vol.16 No. 3, pp.154-166.

Lantos, G.P. (1994), "Faculty Internships: a means to bridge the academician-practitioner gap", Journal of Produce and Brand Management, Vol. 3 No. 4, pp. 5-30.

Linstend, S.A. (1993), "The Sorcerer's Apprentice: problems in establishing student/research credibility as consultant", Personnel Review, Vol.12 No. 4, pp. 3-9. 
Megginson, D., Matthews, J., and Banfield, P. (1993), Human Resource Development, Kogan Page, London.

Redman, T. and Allen, P. (1993), "The use of HRM consultants: evidence from manufacturing companies in the North East of England", Personnel Review, Vol.32 No.2.

Revans, R. (1970), Developing Effective Managers, AppletonCentury-Crofts, New York.

Roberts, K. and Corcoran-Nantes, Y. (1995), "TQM, the new training and industrial relations" in Wilkinson, A. and Willmott, H. (Eds) Making Quality Critical. New Perspectives on Organisational Change, Routledge, London. 